\title{
Cracked tooth diagnosis and treatment: An alternative paradigm
}

\author{
John S. Mamoun ${ }^{1}$, Donato Napoletano ${ }^{2}$
}

Correspondence: Dr. John S. Mamoun

Email: mamounjo@gmail.com

1Private Practice in Manalapan, NJ, USA
2Private Practice in Middletown, NY, USA

\section{ABSTRACT}

This article reviews the diagnosis and treatment of cracked teeth, and explores common clinical examples of cracked teeth, such as cusp fractures, fractures into tooth furcations, and root fractures. This article provides alternative definitions of terms such as cracked teeth, complete and incomplete fractures and crack lines, and explores the scientific rationale for dental terminology commonly used to describe cracked teeth, such as cracked tooth syndrome, structural versus nonstructural cracks, and vertical, horizontal, and oblique fractures. The article explains the advantages of high magnification loupes $(\times 6-8$ or greater), or the surgical operating microscope, combined with co-axial or head-mounted illumination, when observing teeth for microscopic crack lines or enamel craze lines. The article explores what biomechanical factors help to facilitate the development of cracks in teeth, and under what circumstances a full coverage crown may be indicated for preventing further propagation of a fracture plane. Articles on cracked tooth phenomena were located via a PubMed search using a variety of keywords, and via selective hand-searching of citations contained within located articles.

Key words: Crack propagation, cracked tooth syndrome, microscopes, tooth fractures

\section{INTRODUCTION}

A cracked tooth is a tooth in which there exists a partial ${ }^{[1]}$ or complete fracture of a stress plane that commonly occurs in that tooth. A tooth stress plane results from occlusal forces that are commonly imposed on that tooth that may cause, during a masticatory cycle, an instance of higher energy to occur within the stress plane. This instance of higher energy may result in fracture of some of the chemical bonds of the natural tooth structure that traverses the stress plane. With many masticatory cycles, a clinically significant fracture plane may develop on the stress plane. As the fracture plane expands, the rate of fracture of the stress plane theoretically accelerates, due to proportionately increased stress being put on the remaining nonfractured area of the stress plane. With enough fracture area expansion, occlusal forces may become capable of causing the tooth structure around the fractured area to flex, which may result in sensitivity, if the stress plane is contiguous with the periodontal ligament or the pulp chamber, or perhaps if such flexure causes fluid movement within odontogenic processes. ${ }^{[2]}$ Eventually, the stress plane fractures completely, resulting in a tooth piece separating completely along this stress plane. Sometimes, however, a single traumatic hit ${ }^{[3]} \mathrm{can}$ simultaneously initiate a tooth stress plane and also completely fracture that stress plane.

The biomechanical and periodontal prognoses and the treatment requirements of a cracked tooth depend on what aspects of the tooth are intersected by the existing partial fracture of the stress plane, or would be intersected if the stress plane completely fractured. A tooth stress plane or fracture plane may be completely supra-gingival and may or may not intersect the pulp chamber, or may intersect the pulp chamber (potentially causing pulpal necrosis), a furcation (potentially causing tooth root disconnection), a sub-gingival aspect of the root surface (potentially causing chronic periodontal inflammation), or a tooth root (potentially destroying the root or making it impossible to endodontically seal ${ }^{[4]}$ the root). Various

How to cite this article: Mamoun JS, Napoletano D. Cracked tooth diagnosis and treatment: An alternative paradigm. Eur J Dent 2015;9:293-303.

Copyright (c) 2015 Dental Investigations Society.

DOI: $10.4103 / 1305-7456.156840$ 
types of cracks-furcation fractures, cuspal fractures, root fractures, gingival interface fractures, or craze lines may be defined, depending on what structures the stress or fracture planes intersect.

A partial fracture of a stress plane is potentially catastrophic if complete fracture of the stress plane would result in the tooth being nonrestorable with a crown or an endodontic procedure, post/core and crown. A partial fracture is potentially noncatastrophic if complete fracture of the stress plane would result in a tooth that would still be restorable with a direct restoration, a crown, or an endodontic procedure, post/core and crown.

This article reviews the literature on cracked tooth diagnosis and treatment, provides an alternative concept for the description, diagnosis, and treatment of the cracked tooth phenomenon, and assesses the scientific validity of various terms that have been used to describe cracked teeth. Articles were located using a PubMed search, using a variety of keywords related to cracked tooth diagnosis and treatment, and by hand-searching selected citations contained within located articles. Articles were selected (somewhat subjectively, due to the large amount of "expert opinion" in the literature on this topic) based on several criteria: If they added to an evidence-based understanding of the cracked tooth phenomenon; if they are historically important for introducing commonly used terminology and concepts with respect to the cracked tooth phenomenon; if they present insightful clinical examples or case reports of the phenomenon; or if they contain plausible "expert opinion" on this topic.

\section{DIAGNOSING CRACKED TEETH}

Cracked teeth are generally diagnosed by visually observing (ideally using microscopes) ${ }^{[5-7]}$ if a tooth is cracked. A dentist often diagnoses a crack by observing a crack line, which is a line segment from the perimeter of a fracture plane, such that this line segment is also located on a tooth surface that a dentist can observe. Observation of the crack line does not necessarily indicate the fracture plane size and shape. ${ }^{[1]}$ If a direct restoration is observed, such that a crack line is observed to be contiguous with the restoration margin, it may be prudent to remove the restoration to observe the full extent of the crack line underneath the restoration.

The most commonly fractured teeth are the mandibular molars, ${ }^{[8-11]}$ perhaps due to pointy, protruding maxillary molar palatal cusps ${ }^{[12]}$ occluding powerfully into the mandibular molar central grooves. Maxillary premolars, which often have steep inclines on nonfunctional cusps that result in torque forces during mastication, are more likely to crack than mandibular premolars, which experience mostly compression forces due to opposing teeth occluding into the mandibular premolar buccal cusps. A posterior tooth with a class II restoration may be the source of discomfort if it is the only remaining (or restored) posterior tooth in that quadrant, or if it shows signs of occlusal trauma or an abfraction lesion [Figures 1 and 2].

Tooth cracks may not show up on radiographs, ${ }^{[1,10,12-15]}$ since X-ray photons passing through a radiolucent fracture plane also pass through extensive amounts of radiopaque healthy tooth structure. A tooth may be cracked if it shows, on a radiograph, a large peri-apical radiolucency that is contiguous with a furcation, or an entire root surrounded by a radiolucency. ${ }^{[10,16,17]}$

Cracked teeth are often asymptomatic. The pain symptoms that cracked teeth can show are not uniquely associated with cracked teeth but can occur with other causes of tooth pain, such as caries, pulpal pathology, or periodontal disease. Percussion sensitivity, if present, could indicate that the tooth has an irreversible pulpitis or an abscess, which may be associated with a crack. A cracked tooth may not exhibit temperature sensitivity if the crack has caused pulpal necrosis or exhibit sharp pain if a patient occludes on a rubber wheel placed on a suspected cracked cusp. ${ }^{[18]}$ The only consistent sign of a cracked tooth is the existence of a fracture plane within the tooth.

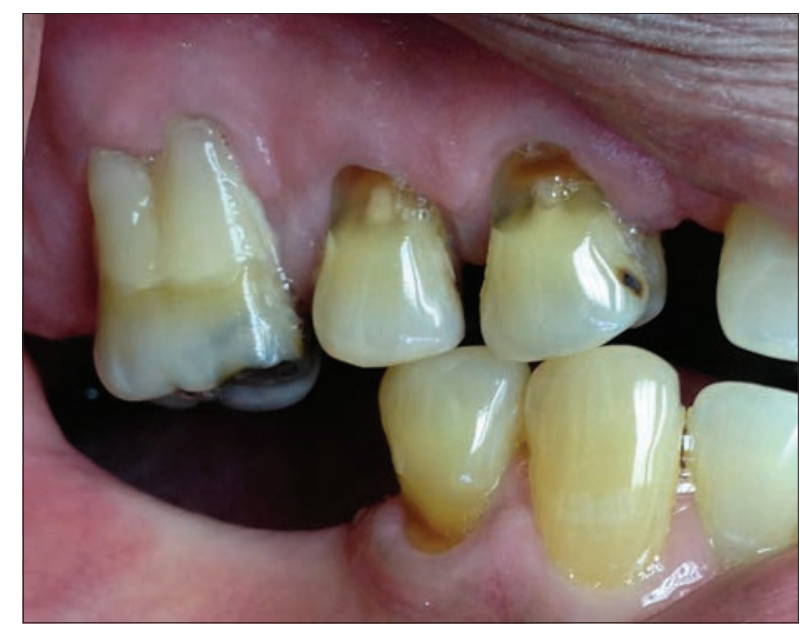

Figure 1: A lateral view of two premolars that experience heavy occlusal forces due to lack of molar occlusion, which also have abfraction lesions 
Hypothetically, caries may accelerate the rate of fracture plane propagation, by weakening tooth structure near a fracture plane. The margins of restorations on cracked teeth should be screened for caries, and carious restorations removed to permit caries removal, crack line observation, and assessment of the tooth's structural integrity.

\section{FURCATION STRESS PLANES}

A furcation stress plane is a stress plane, such that complete fracture of this plane would result in one tooth root becoming completely disconnected from another root. To completely disconnect one root from another, a fracture plane must fracture tooth structure, that is inferior to the pulp chamber floor, that helps to connect those two roots, and also fracture tooth structure superior to the pulp chamber floor, within the buccal and/or lingual and/or mesial and/or distal and/or occlusal walls of coronal tooth structure, that also helps to connect the two roots. Accordingly, a furcation stress plane consists of two subset planes. One subset plane exists inside the volume of tooth structure that is superior to the pulp chamber floor. Another subset plane exists inside a horizontal cross sectional volume that cuts completely through the tooth that is approximately bounded occlusally by the curved surface that is the floor of the pulp chamber, and is also approximately bounded apically by a second curved surface that forms the external underside of the tooth between the tooth roots. Complete fracture of a furcation stress plane fractures tooth structures within, occlusal to and apical to the pulp chamber floor that if intact, would connect one root to another root [Figures 3 and 4]. Observation of a furcation fracture in an asymptomatic tooth (or in a tooth within a quadrant where the patient feels sensitivity but is

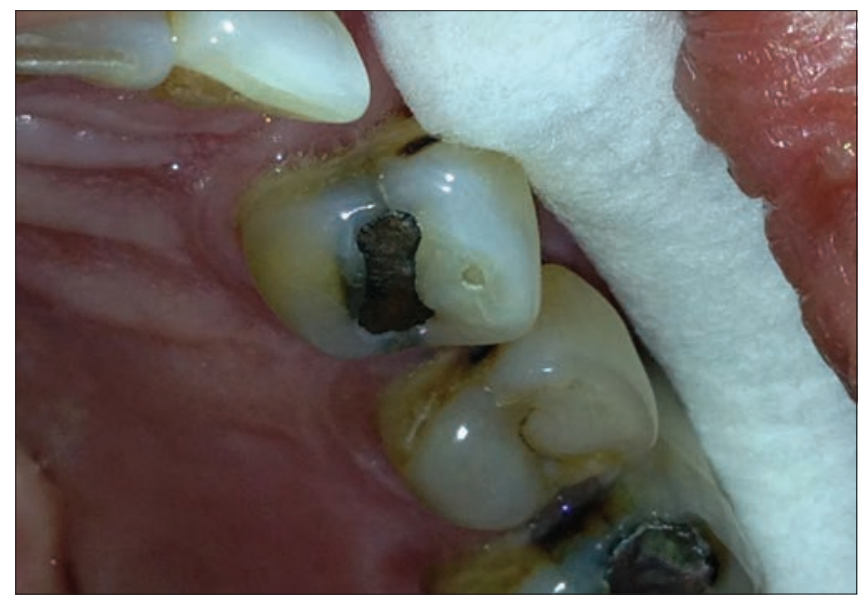

Figure 2: An occlusal view of the premolars from Figure 2 also shows marginal ridge fractures not sure which tooth in the quadrant is causing the sensitivity) is possibly an indication that the tooth is necrotic.

One common example of a furcation stress plane is a stress plane in a posterior tooth that divides the buccal aspects of the tooth structures that are mesial and distal to the pulp chamber, respectively, from the lingual aspects, and that also divides the buccal aspects of the tooth structure that is occlusal and apical to the pulp chamber, respectively, from the lingual aspects. A partial fracture of this furcation stress plane may eventually expand to intersect the pulp chamber and split the tooth into buccal and lingual pieces. Other examples of furcation stress planes include a furcation stress plane that disconnects a distal root from the mesial-buccal and mesial-lingual roots of a mandibular molar, or that separate a mesial-buccal root from the distal and mesial-lingual roots of a mandibular molar. Hemi-section $^{[16,19,20]}$ of roots, followed by endodontic treatment of remaining roots, is sometimes a practical treatment option for furcation fractures, although extraction and placement of an implant may be a more cost-effective and predictably successful treatment.

A furcation stress plane generally is caused by a cusp from an opposing tooth occluding into the central groove of the posterior tooth, resulting in stresses that try to split the tooth into buccal and lingual pieces. These "split-apart" stresses are resisted by the chemical bonds of the tooth structure that binds the buccal aspects of the tooth structures that are mesial and distal to the pulp chamber, respectively, with the

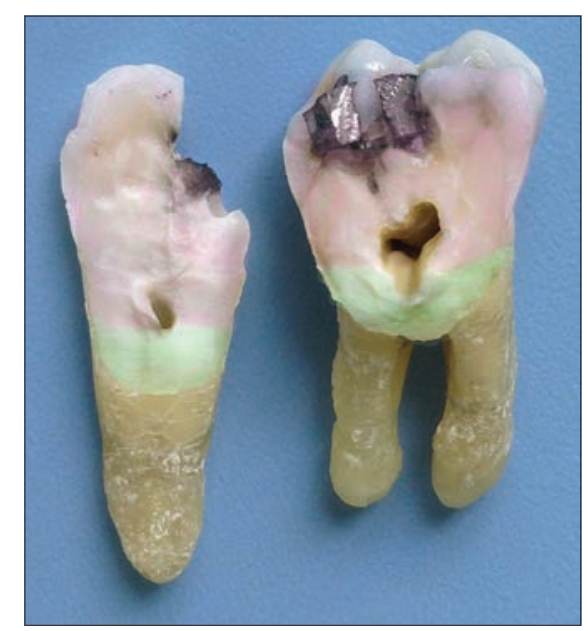

Figure 3: The palatal root (left) disconnected from the buccal roots (right) of this maxillary molar via a furcation fracture. Here, a stress plane superior to the pulp chamber floor (pink) and another stress plane between the pulp chamber floor and the external tooth surface between the roots (green) both fractured, resulting in complete palatal root disconnection 
lingual aspects, and also binds the buccal aspects of the tooth structure that is occlusal and apical to the pulp chamber, respectively, with the lingual aspects. Any posterior tooth restorative preparation that involves removal of the mesial or distal marginal ridges (such as class II preparations), or the tooth structure occlusal to the pulp chamber roof (such as endodontic access openings ${ }^{[21-23]}$ or deep class I preparations), ${ }^{[24,25]}$ results in less tooth structure remaining to resist split-apart stresses. ${ }^{[26-34]}$ Leaving too much soft gutta percha inside a pulp chamber after making a post/core or core build up, instead of filling the entire chamber with a strong core material, may increase the overall flexibility of a molar or premolar tooth, and the long-term rate of furcation fracture plane expansion [Figure 4]. ${ }^{[35]}$

A dentist may observe the unrestored marginal ridge of a two-surface class II restoration to screen for

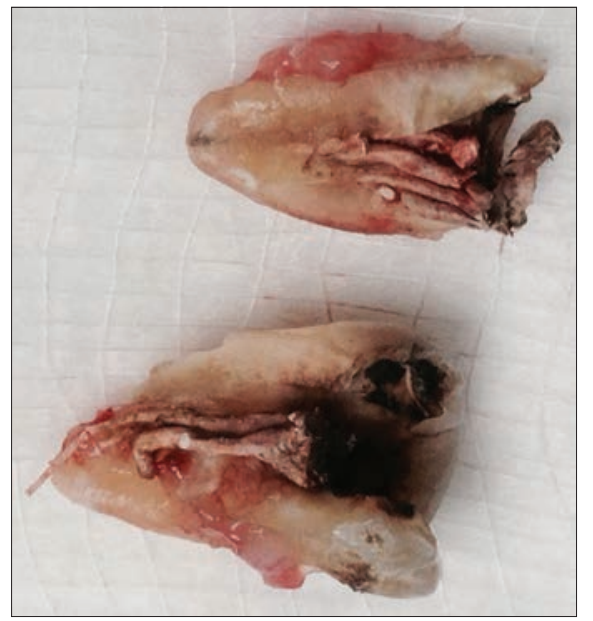

Figure 4: Hypothetically, the furcation fracture in this mandibular molar may have resulted partially from gutta-percha filling much of the pulp chamber, and increasing the flexibility of the pulp chamber walls and floor, compared to if the chamber was filled with a stiff core material

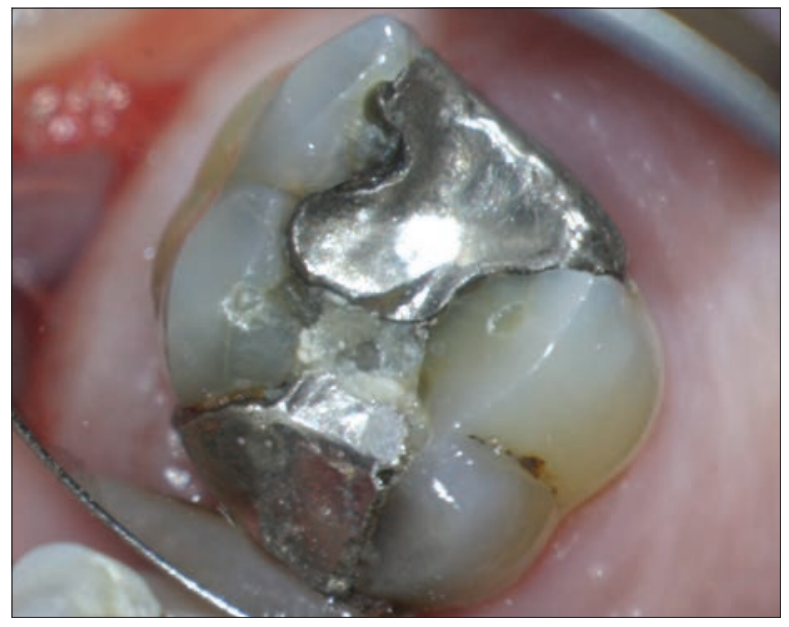

Figure 6: This maxillary molar with a class II restoration was sensitive cracks [Figure 5]. Furthermore, if a tooth with a class II restoration is sensitive, a dentist may remove the restoration to observe if a crack line exists underneath the restoration [Figures 6 and 7]. If no crack line is observed, the dentist (conservatively) replaces the restoration. However, an observed crack line may be interpreted as a partial fracture of a furcation stress plane that is presumed to exist in that tooth, where the tooth has a missing marginal ridge on one side (due to the restoration), and a compromised marginal ridge on the other side (due to the crack). Here, a crown and possibly endodontic treatment may be needed.

\section{CUSPAL STRESS PLANES}

A cuspal stress plane is a stress plane, the perimeter of which is located approximately apical to one cusp, or apical to two or more connected cusps, where

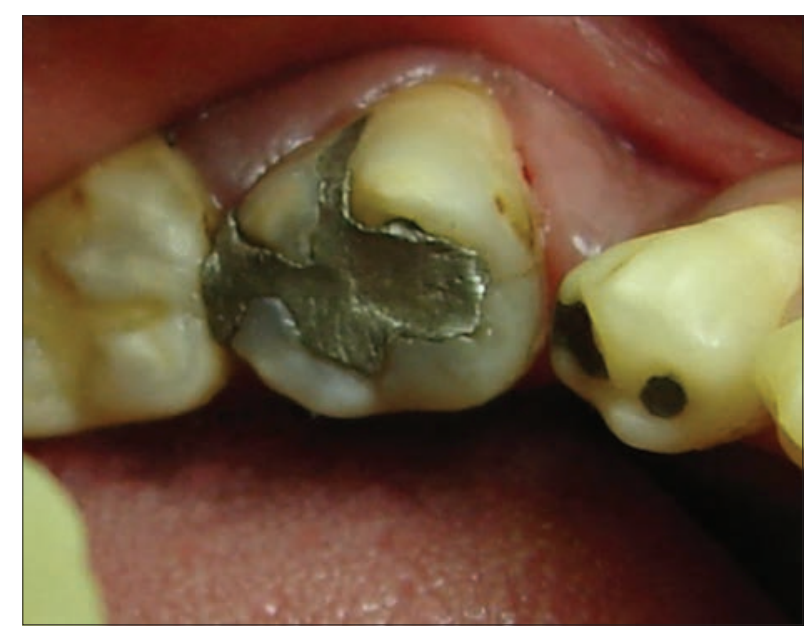

Figure 5: A molar with a class II restoration and a crack in the untouched marginal ridge

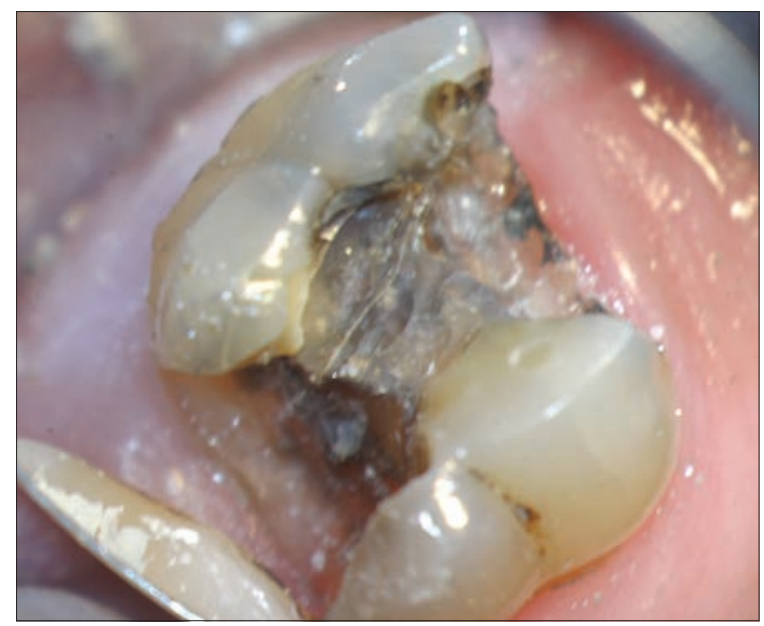

Figure 7: Removal of the amalgam reveals the crack lines of a cuspal fracture plane along the apical-axial aspect of the buccal cusps and a partially fractured furcation stress plane 
the axial aspect of the stress plane may intersect the pulp chamber walls or roof (but does not intersect the pulp chamber floor), and where the lateral aspect of the stress plane intersects the external buccal or lingual tooth surface, and possibly a root, and may be located subgingivally. A cuspal stress plane can be caused by torque forces resulting from occlusion into steep cuspal inclines of cusps located occlusal to the cuspal stress plane. Complete fracture of a cuspal stress plane results in one or more cusps breaking off a tooth [Figure 8]. Complete fracture of a cuspal stress plane that has a subgingival ${ }^{[36-39]}$ aspect may result in a tooth that cannot be restored without the restoration showing permanent periodontal inflammation at the sub-gingival aspect of the fracture.

Cuspal fractures can be caused by forces put on existing restorations during masticatory cycles; these forces stress the stress planes located apical to the cusps that retain the restorations. ${ }^{[32,40]}$ With an amalgam, the preparation axial walls converge toward the occlusal, so occlusally directed forces on the restoration stress the cuspal stress planes. The walls of an inlay preparation diverge toward the occlusal, so apically directed forces stress the cuspal stress planes. If the dentist removes the restoration and observes the dried preparation surface, the dentist may observe a crack line located at what was previously the apical-lateral aspect of the restoration [Figure 7].

Cuspal fracture planes can develop inside a tooth without showing visible crack lines on the external surface of the tooth, if the fracture plane is subgingival, or if the fracture plane has not expanded enough in area to reach the external tooth surface [Figure 9].

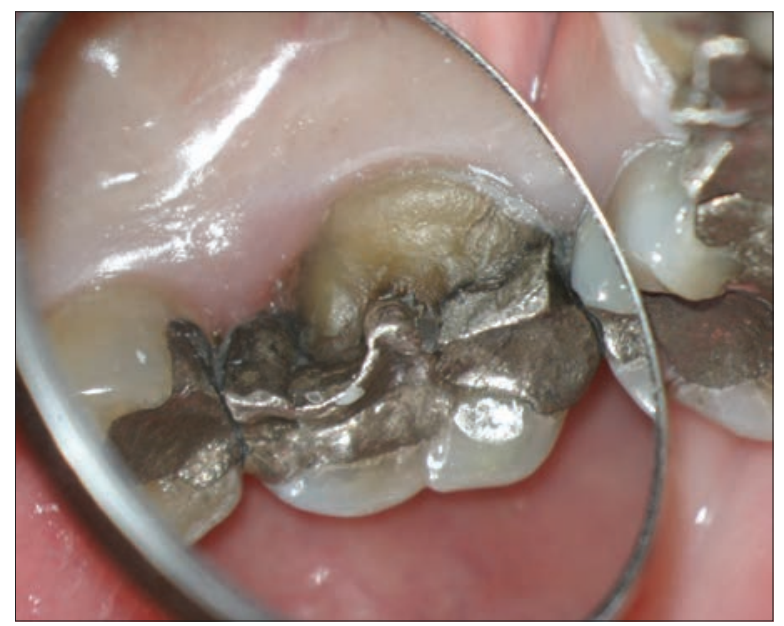

Figure 8: A complete fracture of a molar lingual cusp shows a void that is bounded axially by a large mesial-occlusal-distal amalgam that the cusp was helping to retain
A dentist may not treat such a tooth due to inability to locate a crack line, ${ }^{[41,42]}$ and the tooth may feel sensitive for a long time; later, a cusp may break off, and the sensitivity may consequently end. The diagnosis of a crack in a tooth with no visible crack line requires presumption, and the patient's conviction of which tooth is sensitive. Cementing an orthodontic band ${ }^{[41,43-45]}$ on such a tooth aids in the diagnosis if doing so eventually reduces the discomfort.

A cusp may fracture off the tooth but be retained by gingival tissue [Figure 9]. When the patient occludes, the cracked piece may jab the gingiva but only cause soft tissue pain. Removing the loose piece may indefinitely relieve sensitivity, and with polishing the tooth may be indefinitely stable, without requiring further restoration. When restoring the tooth with a direct restoration, microscopes facilitate observing that an opposing pointy plunger cusp does not occlude into the restoration isthmus.

\section{GINGIVAL INTERFACE STRESS PLANE}

A gingival interface stress plane is a stress plane, the perimeter of which circumscribes the cross section of tooth structure that is located approximately at the interface between the sub-gingival and supra-gingival tooth structure; this plane also intersects the pulp chamber [Figure 10]. The supragingival tooth structure, which is essentially surrounded by air, can rotate freely, in response to occlusal forces that stress this interface, around a fulcrum located at this interface, since the subgingival tooth structure is essentially held firmly by the surrounding alveolar bone and periodontal ligament.

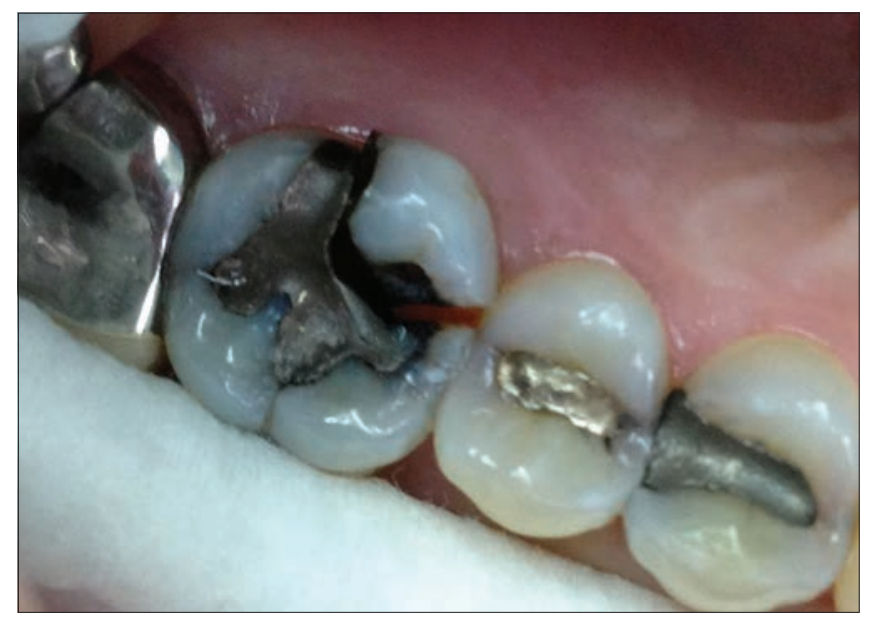

Figure 9: A complete fracture of the mesial-lingual cusp of a maxillary molar, retained only by gingival tissue 


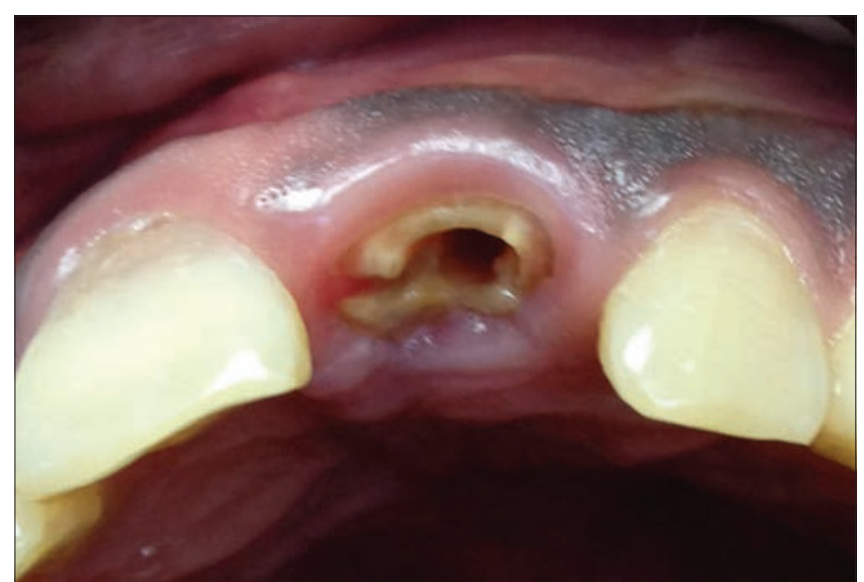

Figure 10: A maxillary central incisor showing a root fracture and a gingival interface fracture, due to a post and core that fractured the root due to lack of ferrule tooth structure

With any crowned tooth, or with any maxillary anterior tooth that receives occlusal forces at the lingual surface, occlusal forces transmit stress to, and may cause fracture of, the cross section of tooth structure located at this gingival interface. ${ }^{[46,47]}$ The tooth cemento-enamel junction (CEJ) and the crown margin usually, but not always, coincide with this interface. Complete fracture of a gingival interface stress plane is often catastrophic, due to such fracture resulting in an anterior tooth with minimal or no ferrule tooth structure.

\section{ROOT FRACTURES}

A root fracture is a fracture of a stress plane contained within only one root, such that complete fracture of the stress plane would not result in disconnection of one root from another [Figure 10]. Root fractures, ${ }^{[3,48]}$ which are often catastrophic fractures, ${ }^{[49]}$ can result from caries in root structure or from roots containing intra-canal retainers ${ }^{[2,50]}$ where the tooth lacks ferrule tooth structure, which results in a post putting more stress on the root. ${ }^{[1,52]}$ Roots can also be fractured via use of excessive pressure while obturating root canals; ${ }^{[33-56]}$ using excessive vertical forces to push a peeso reamer into a root while making a postspace, particularly if the peeso reamer is too wide in diameter compared to the diameter of the canal; skipping sizes of peeso reamers while making a postspace, such as moving from a \#1 peeso reamer directly to a \#3 peeso reamer, particularly when preparing postspaces in thin roots, which are common with premolars or mandibular incisors; or radicular micro-cracks ${ }^{[45,57]}$ created during apico-ectomy procedures using ultrasonic retro-tips. One study ${ }^{[53]}$ showed that the volume and weight of roots are greater factors for increasing root fracture resistance compared to the mesial-disal or buccal-lingual dimensions of roots.

\section{DIRECT VERSUS CUSPAL COVERAGE RESTORATION OF CRACKED TEETH}

If a dentist decides to permanently restore a cracked tooth with a direct restoration, ${ }^{[24,58-61]}$ the dentist may want to adjust ${ }^{[62-64]}$ the bio-mechanical circumstances of the tooth to increase the tooth's resistance to further cracking. If the dentist decides to crown ${ }^{[65,66]}$ the tooth, the dentist may also want to adjust the tooth to stabilize the tooth bio-mechanically in the days or weeks prior to the crown preparation appointment. Such stabilization may be accomplished by reducing, on the cracked tooth, the steep inclines ${ }^{[67]}$ of any nonfunctional or guiding cusps that are in deep overbite with opposing teeth (ideally without exposing dentin), or smoothing the pointy plunger cusps of opposing teeth that are occluding into the cracked tooth, to reduce tensile forces on the tooth. The dentist should maintain the overjet of the maxillary posterior buccal cusps with the mandibular posterior buccal cusps, to prevent cheek-biting that may result from lack of overjet. Ideally, centric contacts should not be removed with such adjustments since this may result in other teeth in the arch re-equilibrating to a different occlusal force distribution. Furthermore, if the opposing tooth occludes only into the cracked tooth, removing centric contacts may induce the opposing tooth to extrude back into occlusion with the cracked tooth. If a partially fractured tooth is not in occlusion or is opposed by a denture tooth, the tooth may last indefinitely. If the patient is young, relatively few years may have been required until an observed fracture plane developed, implying a faster rate of fracture propagation, potentially justifying crown treatment.

A tooth may present with a cusp fractured off and a large restoration that occupies most of the marginal ridge areas and the tooth structure occlusal to the pulp chamber roof [Figure 9]. Here, the natural tooth structure was unable to accept the force load of retaining the restoration without developing a cusp fracture; with the cusp gone, the remainder of the tooth must now accept a larger force load to retain the restoration, which may eventually result in another cusp fracture. The apical aspect of the void left by the fractured cusp may slope to a thin edge towards the apical lateral direction, which hinders preparation of a flat preparation margin, using a $33 \frac{1}{2}$ bur, to provide compression support for the next direct restoration. A radiograph may show a restoration 


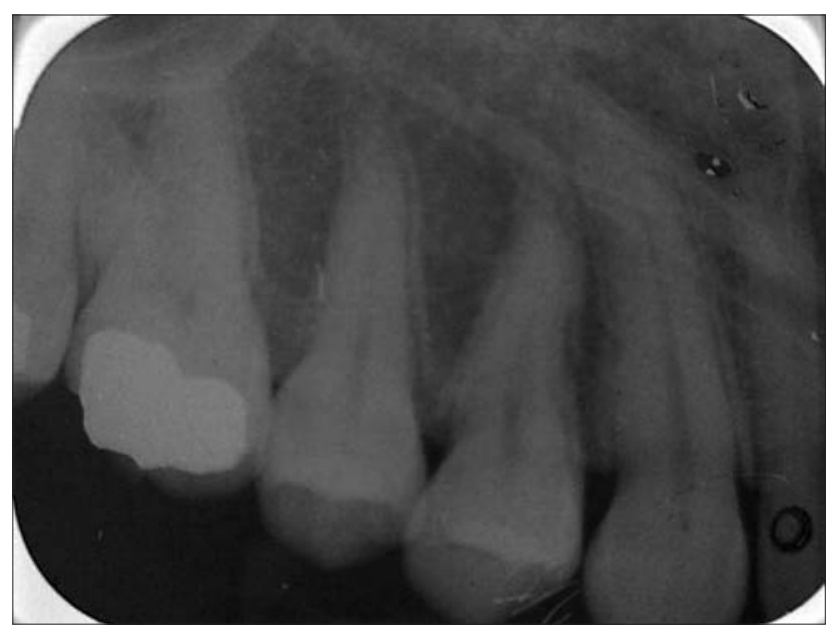

Figure 11: A radiograph of a maxillary molar that contains minimal remaining coronal tooth structure that can help to retain the large mesial-occlusal-distal restoration. The remaining tooth structure is under higher stress levels from retaining the restoration. Part of the distal aspect of the remaining tooth structure fractured, showing that the remaining tooth structure is not strong enough to retain this direct restoration without developing cracks

that is deep in an occlusal-to-apical direction [Figure 11], where there is minimal height of tooth structure from the gingival interface level of the tooth to the apical level of the restoration. A crown and possibly a post may be needed to retain the supra-gingival restoration. However, if the restoration has a buccal or lingual component that reaches the CEJ area of the tooth, then the restoration, on the radiograph, may appear deeper than it is in reality.

A dentist may be tempted to drill out a crack line until the dentist has reached healthy tooth structure, and then place a direct restoration, to seal the tooth structure. However, a crown may be needed to prevent the original causes of the crack from causing further crack propagation. ${ }^{[65]}$ Drilling into a fracture plane by following a crack line theoretically should not substantially reduce the structural stability of the tooth, since tooth structure along a fracture plane is not chemically bonded and therefore does not help to bind the tooth together. Such crack line drilling should be done with a thin bur to ensure a conservative, narrow drilling width that preserves dentin, with microscopes ensuring that the dentist does not drill past the apical extent of the fracture plane.

A crown prevents flexure of weakened supra-gingival tooth structures (thereby slowing or stopping the rate of fracture plane expansion), by transferring the stresses of occlusal forces to the cross section of tooth structure circumscribed by the margin of the crown; this cross section subsequently resists occlusal forces. ${ }^{[51]}$ If this cross section of tooth structure is strong in bond strength, and the abutment has enough ferrule tooth structure and retention, then the crown will be biomechanically stable and should also increase the biomechanical stability of that cracked tooth. ${ }^{[68,69]}$

\section{TERMINOLOGY OF CRACKED TEETH}

Various categorizations ${ }^{[5,36,44,70]}$ and terminologies ${ }^{[1,10,13,37,70-82]}$ have been proposed to describe the phenomenon of cracked teeth. There is no universal agreement among dentists concerning which of these descriptive systems is definitively correct, ${ }^{[83]}$ perhaps due to the inconsistency of symptoms and the seemingly random shapes of fracture planes as they appear clinically. This article proposes describing cracked teeth based on what structures are intersected by stress planes or fracture planes. A comprehensive review of all of the historical descriptions is beyond the scope of this article, although a few comments are presented here.

Cameron claimed that the phenomena of cracked teeth should be defined as a "cracked tooth syndrome." $[8,76]$ However, a tooth crack is not a disease, but is instead a factor ${ }^{[14]}$ that can facilitate periodontal and pulpal disease and biomechanical dental problems. Furthermore, cracked teeth symptoms are inconsistent, ${ }^{[15,18,84-87]}$ a fact that Cameron acknowledged. ${ }^{[8,76]}$ These two realities contradict the scientific rationale for defining cracked teeth as a "syndrome." [83] In his 1964 article $^{[76]}$ in which he invented this term, Cameron arbitrarily stated that "there is a cracked tooth syndrome" but did not, in the article, provide any scientific rationale for using this term, a term which was subsequently adopted by numerous dental authors.

Some authors ${ }^{[18]}$ define "cracked tooth syndrome" as "an incomplete fracture of a vital posterior tooth that involves the dentine and occasionally extends into the pulp." This definition arbitrarily excludes complete fractures of teeth and fractured non-vital teeth from an overall definition of cracked teeth and does not specify the symptoms of cracked teeth, making the term "syndrome" irrelevant.

Some authors ${ }^{[44,88]}$ describe cracks as "vertical," [89] "oblique" ${ }^{[4]}$ or "horizontal." However, one cannot unambiguously differentiate between different crack types based on the "directions" of their fracture planes within a tooth, given that fracture planes are irregularly shaped. 
The term "peripheral fracture," which in the literature $\mathrm{e}^{[44]}$ is used interchangeably with "oblique fracture," is inadequate because one cannot unambiguously distinguish a "peripheral fracture" from a "furcation fracture" according to how these terms are used in the traditional literature. ${ }^{[44]}$ This article substitutes the term "cuspal fracture" for "peripheral fracture" and defines a "cuspal fracture" such that it is clearly distinguishable from a "furcation fracture." Although the concept of a "furcation fracture" is intuitive to experienced dentists, the term "furcation fracture" has not been previously defined in the dental literature, in that this article is the first to precisely define the criteria by which one tooth root can become completely disconnected from another tooth root.

Other authors claim that a crack that only involves enamel is a "nonstructural" craze line ${ }^{[70,80,81,83]}$ that requires no treatment, but a crack that is into dentin is a "structural" crack requiring treatment. ${ }^{[5]}$ This statement, however, requires clarification. Intuitively, a "structural crack into dentin" is a partial fracture that if it became complete, would result in a chunk of tooth structure fracturing off the tooth. However, the fracturing of a piece, per se, or the "direction" of a fracture plane, does not provide information about the endodontic or restoration requirements, or the periodontal, endodontic, or bio-mechanical prognoses, of a cracked tooth. This information is arguably best provided by describing a cracked tooth stress plane based on what tooth structures a partial fracture of that stress plane intersects or would intersect if the stress plane completely fractured.

\section{MICROSCOPES AND CRACKED TOOTH DIAGNOSIS}

The authors recommend using microscopes $(\times 6-8$ magnification or greater) and shadow-free co-axial illumination that is coincident with the dentist's viewing axes, when observing cracked teeth, instead of unaided vision or entry level $\times 2.5$ magnification, or shadow-forming overhead lighting. ${ }^{[5-7,90]}$

Microscopes facilitate observation of microscopic crack lines that may show minimal color contrasts against a desiccated tooth surface [Figure 12], without needing trans-illumination or dyes to observe crack lines. Microscopically precise tactile sensation permits verification of a crack by associating the tactile sensation of an explorer tip falling into a cleft with the microscopic point on a crack line where the tip is located. Microscopes permit detecting microscopic amounts of debris in the cleft, ${ }^{[5]}$ or microscopic differences, in the respective directions of movement, of separate tooth structures shifting independently of one another around a cleft [Figure 13]. Stripping a microscopically thin layer from a surface with a deep craze line may reveal uncracked underlying tooth structure, indicating that the crack is superficial.

Microscopes permit accurate visual estimation of the steepness of cuspal inclines, and allow precise observation of where a pointy lingual plunger cusp occludes into an opposing tooth, and observation if a microscopic crack line is developing around this contact area. Microscopic amounts of chalky white or beige discoloration underneath a cusp can be indicative of caries under the cusp, which sometimes can be overlying a fracture plane. Microscopes facilitate observing microscopic gaps or elevations of restoration margins, which may indicate cracks. Microscopes improve the ability to understand the

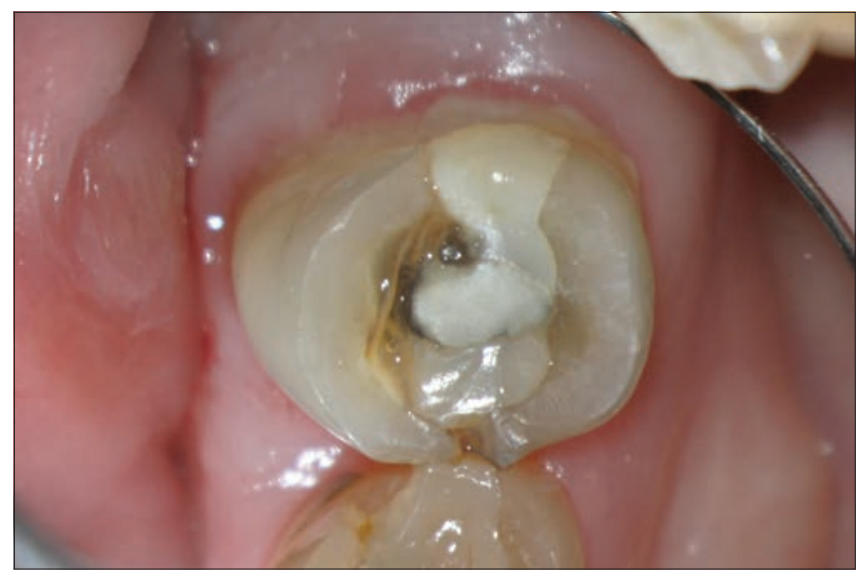

Figure 12: A sensitive premolar shows a cleft and a microscopically thin crack line, with a minimal color contrast with surrounding tooth structure

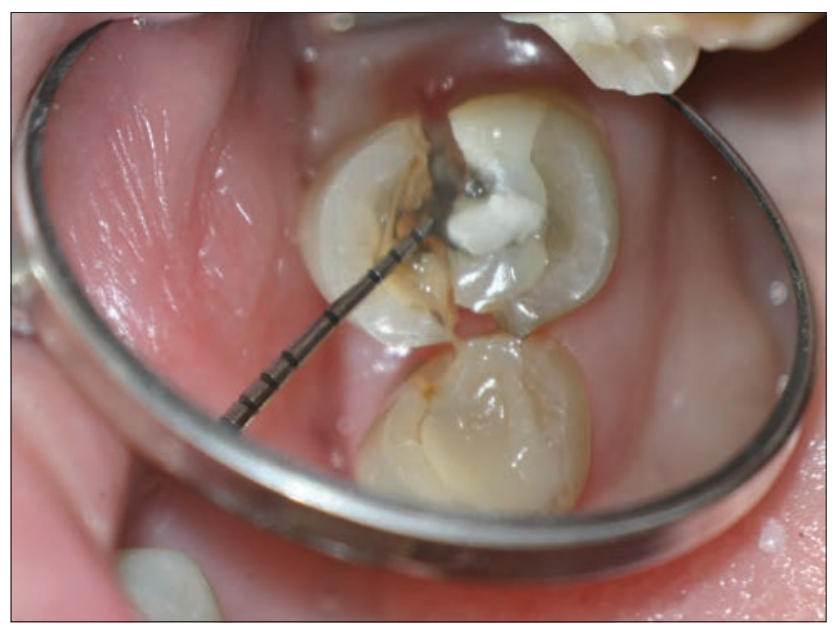

Figure 13: A periodontal probe in the premolar separates the cracked piece 


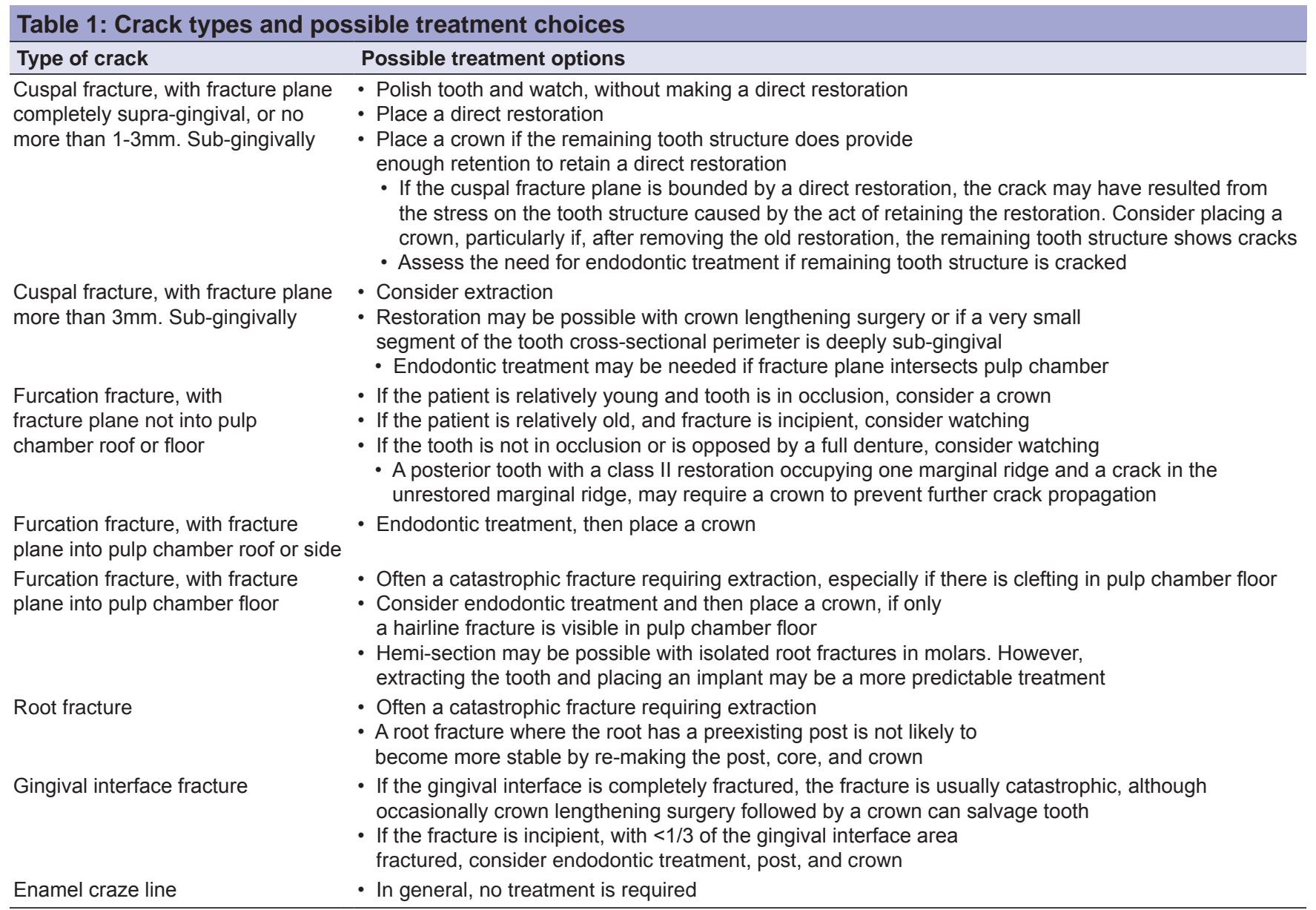

dimensions of foreshortened surfaces. This facilitates observing a marginal ridge crack from an occlusal viewing vantage point, to assess how closely to the gingiva the crack has propagated.

Using microscopes and co-axial illumination, a dentist may drill an exploratory column through a crack line, to observe the depth at which the crack line disappears, or to assess if the crack line extends into the pulp chamber roof. Sometimes, such exploratory drilling may be necessary to allow a dentist to discover that an asymptomatic tooth has a fracture plane that extends into the pulp chamber. Discovering this allows a dentist to diagnose that this asymptomatic tooth has a necrotic nerve. Although such exploratory drilling is not necessarily superior to thermal, and electric pulp testing for diagnosing a necrotic nerve, such exploratory drilling may be a useful diagnostic adjunct if the thermal and electric pulp testing results are inconclusive.

If a fracture plane extends into the pulp chamber floor, this could hinder endodontic sealing of the chamber, although endodontic treatment may last indefinitely.
If the fracture plane clefts the pulp chamber floor, the fracture may be catastrophic.

\section{CONCLUSION}

The periodontal and biomechanical prognoses of a cracked tooth depend on what aspects of the tooth structure are intersected by a partial fracture of a stress plane, or would be intersected if the stress plane completely fractured [Table 1]. The dentist should assess if the fracture plane seems to be expanding at a rate that is fast enough to justify crowning the tooth in the near future, if a crown is needed to stop the factors that seem to be causing fracture plane expansion, if the tooth would be biomechanically stable after crowning, and if an endodontic procedure is needed and is capable of hermetically sealing the cracked tooth.

\section{REFERENCES}

1. Ellis SG. Incomplete tooth fracture - Proposal for a new definition. Br Dent J 2001;190:424-8.

2. Rosen H. Cracked tooth syndrome. J Prosthet Dent 1982;47:36-43.

3. Majorana A, Pasini S, Bardellini E, Keller E. Clinical and epidemiological 
study of traumatic root fractures. Dent Traumatol 2002;18:77-80.

4. De Bruyne MA, De Moor RJ. Influence of cracks on leakage and obturation efficiency of root-end filling materials after ultrasonic preparation: An in vitro evaluation. Quintessence Int 2008;39:685-92.

5. Clark DJ, Sheets CG, Paquette JM. Definitive diagnosis of early enamel and dentin cracks based on microscopic evaluation. J Esthet Restor Dent 2003;15:391-401.

6. Mamoun JS. A rationale for the use of high-powered magnification or microscopes in general dentistry. Gen Dent 2009;57:18-26.

7. van As G. Magnification and the alternatives for microdentistry. Compend Contin Educ Dent 2001;22:1008-12, 1014.

8. Cameron CE. The cracked tooth syndrome: Additional findings. J Am Dent Assoc 1976;93:971-5.

9. Seo DG, Yi YA, Shin SJ, Park JW. Analysis of factors associated with cracked teeth. J Endod 2012;38:288-92.

10. Abou-Rass M. Crack lines: The precursors of tooth fractures-their diagnosis and treatment. Quintessence Int Dent Dig 1983;14:437-47.

11. Kim SY, Kim SH, Cho SB, Lee GO, Yang SE. Different treatment protocols for different pulpal and periapical diagnoses of 72 cracked teeth. J Endod 2013;39:449-52.

12. Ehrmann EH, Tyas MJ. Cracked tooth syndrome: Diagnosis, treatment and correlation between symptoms and post-extraction findings. Aust Dent J 1990;35:105-12.

13. Gibbs JW. Cuspal fracture odontalgia. Dent Dig 1954;60:158-60.

14. Kalyan Chakravarthy PV, Telang LA, Nerali J, Telang A. Cracked tooth: A report of two cases and role of cone beam computed tomography in diagnosis. Case Rep Dent 2012;2012:525364.

15. Turp JC, Gobetti JF. The cracked tooth syndrome: An elusive diagnosis. J Am Dent Assoc 1996;127:1502-7.

16. Moule AJ, Kahler B. Diagnosis and management of teeth with vertical root fractures. Aust Dent J 1999;44:75-87.

17. Barkhordar RA. Treatment of vertical root fracture: A case report. Quintessence Int 1991;22:707-9.

18. Lynch CD, McConnell RJ. The cracked tooth syndrome. J Can Dent Assoc 2002;68:470-5.

19. Langer B, Stein SD, Wagenberg B. An evaluation of root resections. A ten-year study. J Periodontol 1981;52:719-22.

20. Bühler H. Evaluation of root-resected teeth. Results after 10 years. J Periodontol 1988;59:805-10.

21. Howe CA, McKendry DJ. Effect of endodontic access preparation on resistance to crown-root fracture. J Am Dent Assoc 1990;121:712-5.

22. Reeh ES, Douglas WH, Messer HH. Stiffness of endodontically-treated teeth related to restoration technique. J Dent Res 1989;68:1540-4.

23. Reeh ES, Messer HH, Douglas WH. Reduction in tooth stiffness as a result of endodontic and restorative procedures. J Endod 1989;15:512-6.

24. Bearn DR, Saunders EM, Saunders WP. The bonded amalgam restoration - a review of the literature and report of its use in the treatment of four cases of cracked-tooth syndrome. Quintessence Int 1994;25:321-6.

25. Re GJ, Norling BK, Draheim RN. Fracture resistance of lower molars with varying faciocclusolingual amalgam restorations. J Prosthet Dent 1982;47:518-21.

26. Goel VK, Khera SC, Gurusami S, Chen RC. Effect of cavity depth on stresses in a restored tooth. J Prosthet Dent 1992;67:174-83.

27. Khairy MA. Fracture resistance in conservative Class II cavity preparation: Box vs tunnel. Egypt Dent J 1994;40:751-6.

28. Hood JA. Biomechanics of the intact, prepared and restored tooth: Some clinical implications. Int Dent J 1991;41:25-32.

29. Toparli M, Gökay N, Aksoy T. An investigation of the stress values on a tooth restored by amalgam. J Oral Rehabil 1999;26:259-63.

30. Blaser PK, Lund MR, Cochran MA, Potter RH. Effect of designs of Class 2 preparations on resistance of teeth to fracture. Oper Dent 1983;8:6-10.

31. Larson TD, Douglas WH, Geistfeld RE. Effect of prepared cavities on the strength of teeth. Oper Dent 1981;6:2-5.

32. Homewood CI. Cracked tooth syndrome-incidence, clinical findings and treatment. Aust Dent J 1998;43:217-22.

33. Caron GA, Murchison DF, Cohen RB, Broome JC. Resistance to fracture of teeth with various preparations for amalgam. J Dent 1996;24:407-10.

34. Panitvisai $\mathrm{P}$, Messer HH. Cuspal deflection in molars in relation to endodontic and restorative procedures. J Endod 1995;21:57-61.

35. Tennert C, Eismann M, Goetz F, Woelber JP, Hellwig E, Polydorou O. A temporary filling material used for coronal sealing during endodontic treatment may cause tooth fractures in large Class II cavities in vitro. Int Endod J 2015;48:84-8.

36. American Association of Endodontics. Cracking the Cracked Tooth Code. Endodontics: Colleagues for Excellence Newsletter, Fall/Winter: 1997.

37. Hiatt WH. Incomplete crown-root fracture in pulpal-periodontal disease. J Periodontol 1973;44:369-79.

38. Schneider AR, Binder H. Periodontal considerations relevant to treating the fractured tooth. J Prosthet Dent 1984;51:624-7.

39. Polson AM. Periodontal destruction associated with vertical root fracture. J Periodontol 1977;48:27-32.

40. Cavel WT, Kelsey WP, Blankenau RJ. An in vivo study of cuspal fracture. J Prosthet Dent 1985;53:38-42.

41. Batalha-Silva S, Gondo R, Stolf SC, Baratieri LN. Cracked tooth syndrome in an unrestored maxillary premolar: A case report. Oper Dent 2014;39:460-8.

42. Alassaad SS. Incomplete cusp fractures: Early diagnosis and communication with patients using fiber-optic transillumination and intraoral photography. Gen Dent 2011;59:132-5.

43. Pane ES, Palamara JE, Messer HH. Stainless steel bands in endodontics: Effects on cuspal flexure and fracture resistance. Int Endod J 2002;35:467-71.

44. Wright EF, Bartoloni JA. Diagnosing, managing, and preventing cracked tooth syndrome. Gen Dent 2012;60:e302-7.

45. West JD. The cracked tooth syndrome. Dent Today 2002;21:88-97.

46. Heithersay GS, Moule AJ. Anterior subgingival fractures: A review of treatment alternatives. Aust Dent J 1982;27:368-76.

47. McCord JF, Harvie H. An alternative treatment of anterior teeth fractured beneath the gingival margin. Br Dent J 1984;157:320-2.

48. Keçeli TI, Kutlu B, Gungor HC. Preserving alveolar bone growth following cervical root fracture: A case report. J Can Dent Assoc 2013;79:d158

49. Ozcopur B, Akman S, Eskitascioglu G, Belli S. The effect of different posts on fracture strength of roots with vertical fracture and re-attached fragments. J Oral Rehabil 2010;37:615-23.

50. Milot $P$, Stein RS. Root fracture in endodontically treated teeth related to post selection and crown design. J Prosthet Dent 1992;68:428-35.

51. Mamoun JS. On the ferrule effect and the biomechanical stability of teeth restored with cores, posts, and crowns. Eur J Dent 2014;8:281-6.

52. Sorensen JA, Engelman MJ. Ferrule design and fracture resistance of endodontically treated teeth. J Prosthet Dent 1990;63:529-36.

53. Ertas H, Sagsen B, Arslan H, Er O, Ertas ET. Effects of physical and morphological properties of roots on fracture resistance. Eur J Dent 2014;8:261-4.

54. Uzunoglu E, Aktemur S, Uyanik MO, Durmaz V, Nagas E. Effect of ethylenediaminetetraacetic acid on root fracture with respect to concentration at different time exposures. J Endod 2012;38:1110-3.

55. Dang DA, Walton RE. Vertical root fracture and root distortion: Effect of spreader design. J Endod 1989;15:294-301.

56. Harvey TE, White JT, Leeb IJ. Lateral condensation stress in root canals. J Endod 1981;7:151-5.

57. Aydemir S, Cimilli H, Hazar Yoruç AB, Kartal N. Evaluation of two different root-end cavity preparation techniques: A scanning electron microscope study. Eur J Dent 2013;7:186-90.

58. Davis R, Overton JD. Efficacy of bonded and nonbonded amalgam in the treatment of teeth with incomplete fractures. J Am Dent Assoc 2000;131:469-78.

59. Opdam NJ, Roeters JJ, Loomans BA, Bronkhorst EM. Seven-year clinical evaluation of painful cracked teeth restored with a direct composite restoration. J Endod 2008;34:808-11.

60. Eakle WS. Reinforcement of fractured posterior teeth with bonded composite resin restorations. Quintessence Int 1985;16:481-2.

61. Baxter PW. Management of vertical incomplete fractures of posterior teeth with composite resin. Br Dent J 1987;162:219-20.

62. Trushkowsky R. Restoration of a cracked tooth with a bonded amalgam. Quintessence Int 1991;22:397-400.

63. Agar JR, Weller RN. Occlusal adjustment for initial treatment and prevention of the cracked tooth syndrome. J Prosthet Dent 1988;60:145-7.

64. Ito K, Nanba K, Akashi T, Murai S. Incomplete fractures in intact bilateral maxillary first molars: A case report. Quintessence Int 1998;29:243-8.

65. Lin CL, Chang YH, Hsieh SK, Chang WJ. Estimation of the failure risk of a maxillary premolar with different crack depths with endodontic 
treatment by computer-aided design/computer-aided manufacturing ceramic restorations. J Endod 2013;39:375-9.

66. Banerji S, Mehta SB, Millar BJ. Cracked tooth syndrome. Part 2: Restorative options for the management of cracked tooth syndrome. Br Dent J 2010;208:503-14

67. Qian Y, Zhou X, Yang J. Correlation between cuspal inclination and tooth cracked syndrome: A three-dimensional reconstruction measurement and finite element analysis. Dent Traumatol 2013;29:226-33.

68. Guthrie RC, DiFiore PM. Treating the cracked tooth with a full crown. J Am Dent Assoc 1991;122:71-3.

69. Bader JD, Shugars DA, Roberson TM. Using crowns to prevent tooth fracture. Community Dent Oral Epidemiol 1996;24:47-51.

70. Johnson R. Descriptive classification of traumatic injuries to the teeth and supporting structures. J Am Dent Assoc 1981;102:195-7.

71. Thoma KH. Oral Pathology. $4^{\text {th }}$ ed. St. Louis: Mosby; 1954. p. 220.

72. Ritchey B, Mendenhall R, Orban B. Pulpitis resulting from incomplete tooth fracture. Oral Surg Oral Med Oral Pathol 1957;10:665-70.

73. Down $\mathrm{CH}$. The treatment of permanent incisor teeth of children following traumatic injury. Aust Dent J 1957;2:9.

74. Sutton PR. Transverse crack lines in permanent incisors of polynesians. Aust Dent J 1961;6:144-50.

75. Sutton PR. Greenstick fracture of the tooth crown. Br Dent J 1962;112:362-3.

76. Cameron CE. Cracked-tooth syndrome. J Am Dent Assoc 1964;68:405-11.

77. Wiebusch FB. Hairline fracture of a cusp: Report of case. J Can Dent Assoc (Tor) 1972;38:192-4.

78. Silvestri AR. The undiagnosed split-root syndrome. J Am Dent Assoc 1976;92:930-5.

79. Maxwell EH, Braly BV. Incomplete tooth fracture. Prediction and prevention. CDA J 1977;5:51-5.

80. Andreasen JO. Traumatic Injuries of the Teeth. $2^{\text {nd }}$ ed. Copenhagen: Munksgaard; 1981. p. 19.
81. Caufield JB. Hairline tooth fracture: A clinical case report. J Am Dent Assoc 1981;102:501-2.

82. Luebke RG. Vertical crown-root fractures in posterior teeth. Dent Clin North Am 1984;28:883-94.

83. Kahler W. The cracked tooth conundrum: Terminology, classification, diagnosis, and management. Am J Dent 2008;21:275-82.

84. Rivera EM, Walton RE. Cracking the cracked tooth code: Detection and treatment of various longitudinal tooth fractures. American Association of Endodontists. Colleagues for Excellence, Newsletter, Summer; 2008.

85. Nguyen V, Palmer G. A review of the diagnosis and management of the cracked tooth. SADJ 2010;65:396-8, 400.

86. Lubisich EB, Hilton TJ, Ferracane J, Northwest Precedent. Cracked teeth: A review of the literature. J Esthet Restor Dent 2010;22:158-67.

87. Banerji S, Mehta SB, Millar BJ. Cracked tooth syndrome. Part 1 Aetiology and diagnosis. Br Dent J 2010;208:459-63.

88. Dewberry JA. Vertical fractures of posterior teeth. In: Weine FS, editor. Endodontic Therapy. St. Louis: CV Mosby; 1982. p. 8-15.

89. Schetritt A, Steffensen B. Diagnosis and management of vertical root fractures. J Can Dent Assoc 1995;61:607-13.

90. Geurtsen W, Schwarze T, Günay H. Diagnosis, therapy, and prevention of the cracked tooth syndrome. Quintessence Int 2003;34:409-17.

\begin{tabular}{|l|l|}
\hline \multicolumn{2}{|c|}{ Access this article online } \\
\hline Quick Response Code: & Website: \\
& www.eurjdent.com \\
\hline
\end{tabular}

